\title{
Evaluating the Effects of Team Composition and Performance Environment on Team Performance
}

\author{
Harlan E. Spotts \\ Anthony F. Chelte \\ Western New England College
}

\begin{abstract}
Performance, interpersonal relations, equity, and output are examined for both online and face to face team structures. As organizations make wider use of online teams to transcend geographical boundaries and maintain tight cost controls, the question remains whether these innovations are as or more effective than traditional face-to-face group structures. Hypothesized relationships are tested that include the evaluation of the team performance in online groups contrasted to face to face groups; group performance is hypothesized to be higher where membership in the group is selfselected as opposed to assigned group membership; group performance is hypothesized to be highest where its membership is self-selected and face to face. Interaction effects are tested within these hypothesized relationships. Suggestions are made that face to face groups, while a more costly alternative, may have higher levels of performance than online groups over the longer-term. Areas for future research are identified.
\end{abstract}

\section{Introduction}

Organizations have achieved improved efficiencies through technology and more effective utilization of human resources. Teams are an integral part of this new organizational landscape. As the twenty-first century continues to unfold, competitive global pressures will require on-going improvements in productivity, quality, and efficiency. To a large extent, the development and deployment of work teams will undoubtedly be a significant part of the mix (Chelte and Hess, 2000).

There is firm case evidence to suggest that performance teams in organizations are well established. Teams of employees are more productive, more creative, and better able to meet the challenges of an increasingly dynamic business environment than individuals alone (Townsend and DeMarie, 1996). Organizational structures have emerged that provide flexibility, diversity and better access to information for all organizational members. Resource availability, facilitated in part by continual improvements in technology, have established mechanisms for the broader deployment of virtual teams, which are the important element of these new structures (Nemiro, 2000). The use of virtual teams and team networks are becoming dominant structural properties of $21^{\text {st }}$ century organizations.

Formally defined, virtual (or online) teams are groups of geographically dispersed organizational members who communicate and carry out their activities through information technology (Kristof, Brown, Sims \& Smith, 1995; Lipnack and Stamps, 
1997). The traditional organizational structure is undergoing significant change as individuals are finding themselves working in an anywhere/anytime mode, connected to co-workers through information technology (Nemiro, 2000; O'Hara-Devereaux \& Johansen, 1994). The emergence of virtual teams as a "hot" topic in management circles has been widely documented (Matthews \& Gladstone, 2000; Melymuka, 1997; Soloman, 1998; May, 1997). Despite this, little empirical research exists that explores the dynamics, strengths and limitations that may be inherent in the virtual work environment (Furst, Blackburn \& Rosen, 1999).

There is disagreement over the efficacy of virtual teams. For example, Glacel (1998) raises the question as to whether virtual teams can "really exist." She contends that "given the strict definition of teams, virtual teams exist only with great difficulty, if at all. For virtual teams to "evolve" and develop, a "firm foundation of face-to-face relationship building is essential and serves as a prerequisite for virtual teaming" (1998:12). Others have suggested that specialized training is necessary to ensure that individuals can function effectively as virtual team members. The virtual team environment may also be lacking in critical non-verbal aspects of communication and traditional cues of social interaction such as body language and hand gestures that are lost in even the best teleconferencing and communications systems.

Anecdotal support for the value-added contributions of virtual teams stems from individual corporate experiences related in the literature. The academic literature is still developing and consensus on virtual team efficacy is still lacking. As organizations continue to globalize and simultaneously reduce costs, it appears that virtual teaming will become a permanent fixture of the organizational landscape. Organizations continue to make wide-use of performance teams to participate in decision-making. Many business decisions are now made by work teams rather than by individuals. Empirical investigation of team dynamics in the virtual environment has become more pressing. Critics of the effectiveness of virtual teams stress the need for balance between high-tech and high-touch interaction among team members

In academic environments, the widespread use of teams has been well established. As on-line education has become available to a much wider global audience, the use of "teams" is necessarily "virtual." To be sure, student teams (whether online or face-toface) experience many problems that may have an impact on team performance. It has been well established that poorly defined goals and expectations, mismanaged conflict, team member dissatisfaction and poor communication have potential dysfunctional effects on student team performance (Cox and Bobrowski, 2000). Yet, when deployed effectively, student teams can increase productivity, raise morale and encourage innovation. Effective team management by team members is the key element in minimizing dysfunction and enhancing the likelihood of a positive performance.

Business schools have embraced the team concept as an important instructional element in the delivery of the curriculum. This has provided students with opportunities to "experience" teamwork as part of their formal academic training and career preparation. In addition to the potential for helping students develop interpersonal skills 
and the understanding of different perspectives (Goldfinch, Laybourne, MacLead \& Stewart, 1999; Michaelson \& Razook, 1999; Chelte, 2003), team projects may also enhance student learning of course content (Tinto, 1999). However, evidence strongly suggests that assigning team projects is not sufficient. Students benefit most from a design that incorporates team-building skills and skills required to overcome barriers to effectiveness (Feichtner \& Davis, 1985; Bacon, Stewart \& Silver, 1999; Bolton, 1999; Ettington \& Camp, 2002; Tonn \& Milledge, 2002).

Business schools are responsible, in part, to respond to stakeholder needs and to facilitate the development of leaders and effective organizational members. The incorporation of virtual teams as an experiential component in online (and traditional face-to face) education, is consistent with these goals. Courses that include virtual teaming have the potential to involve students in experiences which are not available in conventionally structured courses that use teams. Virtual team experience may offer students opportunities to develop skill-sets appropriate for future organizational challenges (Chelte, 2003).

Teams are important in attaining organizational and managerial goals. Business schools and organizations clearly recognize their value. When deployed effectively, teams can increase productivity, raise morale, improve satisfaction, increase commitment, decrease turnover and absenteeism, and encourage innovation (Chelte, 2003).

\section{The Research Framework and Design}

The current paper proposes to investigate team performance in online and face to face group environments. As part of the design, we will explore the relative impact that group self-selection vs. "assigned" membership have on group performance. Thus, at its simplest level, the experimental design for the research is a 2 by 2 factorial (online vs. face to face, and, assigned vs. self-selected groups). Overall group performance will be measured through a multi-dimensional scale of evaluation discussed in previous research (cf Chelte, 2003).

At a basic level, the following hypotheses will be considered:

1. Evaluations of group performance will be higher in virtual groups than in traditional groups (group type = main effect).

2. Evaluations of group performance will be higher where membership in the group is self-selected than in groups where membership is assigned (group composition $=$ main effect $)$.

3. Evaluations of group performance will be higher where group membership is selfselected and "face to face" than in any of the other conditions, with assigned group membership in the face to face setting having the lowest performance evaluations (group type by group composition = interaction effect). 
The hypotheses are based on the following suppositions:

Online group environments have a higher level of group performance documentation, thus allowing individual team member contributions to be monitored. This allows for tracking of those who tend toward "social loafing" and those who perform. The level of electronic accountability could act as a motivator for members to participate more frequently (group members know that their contributions are electronically tracked).

The face to face group environments have a certain level of accountability in that faceto-face interactions will keep members involved. However, once the group disperses there is no outside monitoring taking place to serve as a motivator to perform.

In the assigned membership versus the self-selected situations, members "assigned" to a particular group have potentially less "invested" personally. Self-selected groups, on the other hand, may have personal relationships that come into play to maintain group performance.

Exploratory considerations seek to determine whether virtual, self-selected membership groups are more or less efficient than traditionally structured, self-selected membership groups. Perhaps what matters most is not the environment that the group operates in but how the composition of the group is determined (self-selected vs. assigned). To what extent do personal bonds matter in group efficiency? Does the environment (online vs. face to face) have a measurable impact on the strength and cohesiveness of personal bonds? Perhaps in the virtual setting, members may be familiar with others' work behavior but may not necessarily have developed personal bonds. These are questions that will be explored in depth in this investigation.

\section{Method \& Analysis}

A survey was administered to 36 students enrolled in a graduate business course delivered in either an online or face to face format. Approximately one third of the subjects were in the online section of the course. Throughout the course, students were required to work in four different teams. Thus, in the offline class there were four teams of four or five students, with the team composition changing for each of the four assignments.

The first three team assignments revolved around extensive class exercises working with a computer-based simulation. These team assignments lasted approximately two weeks and required both a global and individual team evaluations after the assignment was completed. Each of these first three teams in which the students worked were composed by random assignment implemented by the instructor. Students had no say as to team composition. The last team assignment required student teams to compete against each other as they managed a computer-simulated company across 9 periods of play. These last teams were composed by allowing students to self-select their teams. Since students worked with most students in the class across the first three assignments, it was assumed that they had enough prior knowledge about other 
students' teamwork behavior and personality style to make a reasonable decision as to with whom they would like to work.

All team assessments were collected by using an online form administered through a virtual classroom environment. The same virtual classroom platform is used at this institution for both online and face to face courses. Thus, these classrooms become a communication support vehicle for students meeting face to face. This virtual classroom environment is used extensively throughout courses in the graduate business program, so students are very familiar and comfortable using the platform.

After each team assignment students completed two assessments of team performance, a "global" assessment and "individual" assessment. The global assessment consisted of 34 items measuring perceptions of "Team as a whole" performance on a variety of activities and behaviors. A factor analysis of the 34 items resulted in a four factor structure reflecting the dimensions of Team Efficiency, Interpersonal Issues, Equity in Participation, and Outputs of Effort. These factors were not orthogonal. The individual assessment asked for each team member to evaluate the participation of individual team members. This assessment included "letter grade" and "dollar compensation" measures. So, each member could receive a letter grade from "A" to " $F$ " and a compensation amount from " $\$ 0$ " to some portion of a $\$ 25,000$ pool distributed across four or five team members.

In addition to the two team assessments, two objective measures of performance were included in the study. First, the virtual classroom has rooms that student teams can use to communicate on projects. For students enrolled in the online course, these rooms were their primary source of communications. A virtual chat routine was used on occasion, but not extensively by these students as a primary communication channel. For students enrolled in the offline course their primary means of communication were weekly, face-to-face meetings in class. The virtual team discussion room was used by these students as a "supplemental" communications channel between classes. Thus, postings to these virtual team rooms by students were used as a measure of team activity. Since each team had a different room through out the semester for each one of the assignment teams, a historical record was kept of individual team and individual team member activity.

A second objective measure of performance was abstracted from the computer simulation used in the course. Being a competitive simulation, each team managed their company in direct competition with their classmates. So, there were, in effect, winners and losers in the simulation. The results of this simulation were used to develop a score that ranged from 0 to 100 for each of the eight teams across the two courses. This was determined by creating a weighted score for company performance based on cumulative net income generated, final overall market share, and an efficiency index dividing marketing expenses by net income. 


\title{
Hypotheses:
}

The specific hypotheses related to team performance, postulating main and interaction effects. Specifically, it was expected that there would be a main effect for online versus face to face team performance, with higher evaluations in the online teams than in offline teams. A second main effect was expected for team composition, instructorassigned versus student self-selected. It was expected that team performance would be higher in student self-selected teams than instructor-selected teams. Finally, an interaction effect was expected, with team performance being highest in self-selected and offline teams, than in any other condition. The lowest evaluations would be in offline, instructor assigned teams.

\section{Results:}

The 34-item global measure was subjected to a factor analysis. Scale purification lead to retaining 25 items that cleanly loaded on four factors (see Exhibit 1). Principle axis factoring uses estimated communalities in the analysis, making it difficult to determine absolute variance explained; however, the four factors were estimated to explain approximately 60 percent of the variance in the data. Each factor was subjected to a reliability analysis, with resulting Cronbach's alpha scores between .88 and 1.0.

\section{Exhibit 1}

\section{Factor Analysis Results of Global Team Assessment Measure}

\author{
members are imaginative \\ Understand range of skills etc. \\ Diff-Sims effectively harnessed \\ team agrees on goals and objectives \\ members articulated a clear set of goals \\ team has effective work structure \\ team devised effective time tables \\ Members view themselves as team \\ Members participate in decision making \\ Team members take turns leading \\ members have resources etc. \\ Members take arguments personally \\ team often disagrees about ideas \\ goals are not motivating to members \\ Team members are not effective decision makers \\ Team cannot integrate diverse \\ team meetings are not productive \\ not clear what members should do \\ a few members do most of the work* \\ Members do their fair share* \\ team has clear leader* \\ Quality of team work is superior \\ Quantity of team work is superior \\ We have met the needs of our client \\ Percent Variance Explained \\ Eigenvalue \\ Cronbach's alpha
}

Performance
.785
.758
.730
.689
.685
.665
.623
.587
.583
.534
.440
.326

Interpersonal Issues Equity Output

$$
\begin{aligned}
& .785 \\
& .758 \\
& .730 \\
& .689 \\
& .685 \\
& .665 \\
& .623 \\
& .587 \\
& .583 \\
& .534 \\
& .440 \\
& .326
\end{aligned}
$$

$\begin{array}{cccc} & .836 & & \\ & .670 & & \\ & .647 & & \\ .595 & & \\ & .581 & & \\ & .575 & & \\ & .492 & .702 & \\ & & -.685 & -1.004 \\ & & .343 & -.826 \\ & & & \\ & & & .663 \\ & & & .70 \\ 43.48 & & 5.10 & .92 \\ 10.872 & 7.61 & 1.28 & \\ .92 & 1.90 & 1.0 & \end{array}$

- One of the items loading on the equity dimension has a negative loading. While it appears that an inconsistency exists, the valence of the items is consistent with the way in which the items were scored. Item responses were scaled $1=$ disagree to $5=$ 
agree. Thus, Members doing their fair share was scored closer to 5 (mean $=4.18$ ) while a few members do most of the work was scored closer to 1 (mean =1.95). The evaluation of the team not having a clear leader scored in between (mean = 3.36). If all members were doing their fair and the team was operating efficiently, then the perception of having a leader would have been low.

Values for the retained variables were summed to create four composite variables subsequently used in a $2 \times 2$ MANOVA. Independent factors included Course Format (online versus face to face) and Team Composition (instructor-assigned versus student self-selected). The MANOVA indicated statistically significant results for the main effects due to Course Section (Pillai's Trace $=.093, F=2.887, \mathrm{df}=4,113, p=.026$ ) and Team Composition (Pillai's Trace $=.093, \mathrm{~F}=2.887, \mathrm{df}=4,113, \mathrm{p}=.026$ ). The interaction effect between Course Format and Team Composition was not statistically significant.

An examination of ANOVAs revealed a statistically significant difference for the Interpersonal Team Issues $(F=8.326, d f=1,116, p=.026)$ for Course Format. For Team Composition the factors related to Team Performance $(F=5.028$, df $=1,116, p=$ .027 ) and Equity in Member Participation ( $F=7.457, \mathrm{df}=1,116, p=.007)$ were statistically significant. The fourth factor, Team Output, was marginally statistically significant $(F=3.324, d f=1,116, p=.071)$.

An examination of the means response for the summated factor of Interpersonal Team Issues indicated that the students working in virtual teams were slightly less positive about their perceptions of interpersonal team relationships than were students working in face-to-face teams (see Table 1). Not surprisingly, it was found that student perceptions of Team Effectiveness were greater for student self-selected teams than in instructor-assigned teams. Equity in Team Member Participation exhibited the same pattern as did Team Effectiveness. Finally, perceptions of Team Output were also higher for student self-selected than Instructor-assigned teams (see Table 1).

Table 1

Results of Team Composition Across Course Format on Perceptions of Effectiveness, Interpersonal Issues, Equity and Output

\author{
Course Format \\ Online Section
}

Performance

Interpersonal

Issues

Equity

\subsection{4}

\section{Face to Face Section

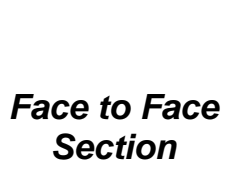

Output

${ }^{*}$ Statistical significance of simple main effects based on ANOVA results reported above
Team

Composition
Instructor-
Assigned

48.58

52.48

\section{Student Self- Selected}

12.303
12.33

9.35

10.22

13.26 
Although the interaction between Course Format and Team Composition was not statistically significant, the pattern of mean responses was in the expected direction. Students working in face to face, self-selected teams had the highest self-perceptions of team performance (54.375), followed by Online, student self-selected teams (50.583). Face to Face, Instructor-assigned teams had the lowest mean level self-perceived performance (48.06).

Student self perceptions of team performance, interpersonal issues, equity and output always provide interesting perspectives on the participants feelings about team performance. Interestingly enough, all teams felt that they were producing relatively high quality output, high quantity and delivered what the client wanted. However, in looking at team performance there were statistically significant differences between the virtual and face-to-face teams in the level of team activity throughout the semester. A MANOVA of team activity as measured by message activity in the virtual classroom revealed a simple main effect for Course Format (Pillai's Trace $=.224, \mathrm{~F}=20.068$, df $=$ $2,139, p<.001$ ), with face to face teams generating a much higher level of team activity than Online teams. There was also a simple main effect for Team Composition (Pillai's Trace $=.598, \mathrm{~F}=103.290, \mathrm{df}=2,139, \mathrm{P}<.001$ ), with student self-selected teams generating more activity than instructor-assigned teams. As for the interaction, it was significant (Pillai's Trace $=.184, F=15.722$, df $=2,139, p<.001$ ), where face to face, student self-selected teams had the highest level of both team and individual contributions to team activity. The lowest level of activity occurred among Online, instructor-assigned teams (see Table 2).

Table 2

\section{Team Activity Assessed via Virtual Classroom Across Course Format and Team Composition}

\begin{tabular}{|c|c|c|c|c|}
\hline & $\begin{array}{l}\text { Course Format } \\
\text { Online Section }\end{array}$ & $\begin{array}{l}\text { Face to Face } \\
\text { Section }\end{array}$ & $\begin{array}{c}\text { Team } \\
\text { Composition } \\
\text { Instructor- } \\
\text { Assigned }\end{array}$ & $\begin{array}{l}\text { Student Self- } \\
\text { Selected }\end{array}$ \\
\hline $\begin{array}{l}\text { Overall Team } \\
\text { Activity }\end{array}$ & $51.64(b, d)$ & $195.73(a, d)$ & $46.39(b, c)$ & 109.62(a,c) \\
\hline $\begin{array}{l}\text { Individual Team } \\
\text { Member activity }\end{array}$ & $11.00(c)$ & $40.78(a, c)$ & $10.00(b)$ & $23.77(a, b)$ \\
\hline
\end{tabular}

Significant differences labeled a, b, c, d

\section{Discussion and Conclusions}

The global team assessment measure yielded four distinct factors. Each factor relates to an important aspect of overall team performance. The elements that emerged include team performance, interpersonal issues, equity, and output. The importance of 
these elements have been demonstrated in previous research. Sixty percent of the variance was explained by the four factors. For social science research, this is a robust finding. Future research will demonstrate whether these four factors have applicability across larger sample sizes and for a variety of different groups.

As predicted, there was a significant main effect for online team evaluations performance. This indicates that online teams perceive themselves as more cohesive with greater levels of contribution from all. This could be due, in large measure, to the high degree of accountability present in the online environment. Documentation of group performance (ie individual contributions) can and are monitored. In the electronic classroom platform, all formal interaction among team members is "recorded" providing a transcript for later review. This can be accessed directly by the team members as well as by the instructor. Other studies have observed a direct correlation between accountability and perceived team performance (Bowes-Sperry, Kidder, Foley, \& Chelte, 2004). In the face to face condition, there is no formal documentation of contribution.

Whether teams self-select members or were assigned members by the instructor also yielded significant effects. Self selected teams have membership that may be more fully and personally vested by the participants. That is, individuals may align their psychic selves and their personal investment in the overall performance of the team. When the instructor "assigns" team membership, individuals may have less personal investment, little or no history with other members, and a less direct personal stake in the outcomes of group performance. This may lead to lower levels of team performance. In the current study, however, the interaction effects between team format (online vs. face to face) and team composition (self selected vs. instructor assigned) were not significant. Future research needs to examine this interaction effect across more observations to determine whether there is a potential salient effect of these interactions.

It must be acknowledged that these results are preliminary in nature due to the sample size restrictions on the experimental design. The low sample size may have played a role in rendering some relationships statistically insignificant. It must be noted, however, that mean levels of performance evaluation were in the expected direction even though there was a lack of statistical significance. Sample size may also have an impact on the factor structure, which should be verified in future research. In a very recent study, similar constructs were examined including team empowerment, customer satisfaction, process improvement, and task interdependence. A major focus of this study was directed to the impact of the frequency of face-to-face meetings on team effectiveness (measured by customer satisfaction). Interestingly, the frequency of face to face meetings had some measurable impact on team empowerment (an internal perceptual construct) but no effect on team performance indicated by customer satisfaction (Kirkman, Rosen, Tesluk, and Gibson, 2004). It is clear that more focused research needs to be oriented toward interaction effects and moderating effects of a broad set of team-based variables. 
The exploratory question in this study was whether online and self-selected teams have higher levels of performance than face to face, instructor assigned counterparts. The impact of the environment (online vs. face to face) did have an effect. Students working in virtual teams were less positive about their perceptions of interpersonal team relationships. It appears that face to face, self-selected teams have the highest degree of satisfaction and perceived efficiency.

This last finding is consistent with previous studies that have shown that students have a tendency to reject virtual teams when provided the opportunity. That is, there is a marked preference for working in a face-to-face, off-line environment, when provided the opportunity (Chelte, 2003).

This raises an interesting and challenging question for the wide use of online teams across organizations. Do online teams, while more cost-effective in the short-run, have a higher level of performance? Do virtual teams take full advantage of all the human resources available to them? Even where there is increased accountability, it appears that the overall perception of performance and satisfaction is lowest where team membership is online and "assigned."

Future research should critically examine the role of online teams in achieving organizational goals. While globalization may motivate organizations to take advantage of technology and short-term cost reductions in deploying teams across virtual geographical boundaries, they may do so at the longer-term expense associated with lower levels of performance and satisfaction. 


\section{References}

Adams, N. (1995) Lessons From the Virtual World Training, June: 45-48.

Ancona, D., T. Kochan, M. Scully, J. Van Maanen, D. Westney, D. Kolb, J. Dutton, \& S. Ashford. (1999) Managing for the Future: Organizational Behavior \& Processes. South-Western College Publishing,.

Bacon, D.R., Stewart, K.A., \& Silver, W.S. (1999) Lessons From the Best and Worst Student Team Experiences: How a Teacher Can Make the Difference. Journal of Management Education. 23, 467-488.

Bolton, M.K, (1999) The Role of Coaching in Student Teams: A "Just-in-Time Approach to Learning Journal of Management Education, 23, 233-250.

Bowes-Sperry, L., Kidder, Foley, \& Chelte, A.F. (2004) Just on a Team or on a Just Team? Procedural Justice Effects on Perceived Student Learning. Unpublished.

Byrne, J. (1995) Virtual B-Schools--Beaming Classes to Companies From Daewoo to Disney. Business Week. October 23, 64-68.

Chandler, Alfred D. (1962) Strategy and Structure. Cambridge, MA: MIT Press. .

Chelte, A.F. (2003) Challenges of Virtual Teams in the Classroom The Journal of Behavioral and Applied Management. Winter, , Vol 4(1):122-133.

Chelte, A.F. (2003) Traditional Teams Trump the Virtual Alternative Journal of Business and Behavioral Science. Spring, Vol 10(1):50-61.

Chelte, A.F. and P. Hess. (2001) Tradition, Technology and Faculty Partnership: An Integrated Approach to Course Delivery. The Journal of Behavioral and Applied Management, 2:151.

Cox, P. and P.E. Bobrowski. (2000) The Team Charter Assignment: Improving the Effectiveness of Classroom Teams. The Journal of Behavioral and Applied Management, 1:92.

Cramer, S.F. (1994) Assessing Effectiveness in the Collaborative Classroom. New Directions for Teaching and Learning. , 59:69-81.

Davis, S. and J. Botkin, (1994) The Coming of Knowledge-Based Business," Harvard Business Review. Volume 72, September-October: 170.

Ettington, D.R. \& Camp, R.R. (2002) Facilitating Transfer of Skills Between Group Projects and Work Teams. Journal of Management Education, 26: 356-379. 
Feichtner, S.B., \& Davis, D.A. (1995) Why Some Groups Fail: A Survey of Student Learning Experiences With Learning Groups. The Organizational Behavior Teaching Review, 9: 58-71.

Feldman, D.C. (1984). The Development and Enforcement of Group Norms. Academy of Management Review, 9:47-53.

Furst, S., R. Blackburn \& B. Rosen. (1999) Virtual Team Effectiveness: a Proposed Research Agenda" Info Systems Journal,. 9:249-269.

Gersick, C.J. (1988) Time and Transition in Work Teams: Toward a New Model of Group Development. Academy of Management Journal,. 31:9-41.

Glacel, B.P. (1998) Virtual Teams Create New Challenges. Business Journal, : 12-13

Goldfinch, J., Laybourne, P., MacLeod, L., \& Stewart, S. (1999). Improving Group Working skills in Undergraduate Education Through Employer Involvement. Assessment and Evaluation in Higher Education, 24: 41-51.

Hilton, C. and N. Kameda. (1999) E-Mail and the Internet as International Business Communication Teaching and Research Tools--A Case Study. Education for Business. . January/February.

Ives, B. and S.L. Jarvenpaa, (1996) Will the Internet Revolutionize Business Education and Research? Sloan Management Review. Spring,: 33-41.

Katzenbach, J.R. \& D.K..Smith. (1993) The Wisdom of Teams. Harvard Business School Press.

Kirkman, Bradley, L., Benson, R., Tesluk, P. and Gibson, C. (2004) The Impact of Team Empowerment on Virtual Team Performance: The Moderating Role of Face-ToFace Interaction. The Academy of Management Journal. Volume 47, \#2, April: 175192.

Kristof, A., K. Brown, H. Sims, and K. Smith. (1995) The Virtual Team: A Case Study and Inductive Model. In M.Beyerlein \& D. Johnsons (Eds), Advances in Interdisciplinary Studies of Work Teams: Knowledge Teams the Creative Edge. , Greenwich, JAI Press.

Lipnack, J. and J. Stamps. "(1999) Virtual Teams. Executive Excellence. , Vol. 16 \#5: 14-16.

Matthews, J. and B. Gladstone. (2000). Extending the Group: a Strategy for Virtual Team Formation." Industrial and Commercial Training, \#32:24-29.

May, M. (1997) Preparing Organizations to Manage the Future. Management Accounting. 28-32. 
Melymuka, K. (1997) .Virtual Realities. Computerworld, 70-72.

Michaelson, L.K. \& Kazook, N.M. (1999) Making Learning Groups Effective Selections: 16, 28-35.

Miesing, P. (1998) Using Electronic Networks in Management and Executive Learning" Journal of Workplace Learning, . \#10:324-327.

Nemiro, J. (2000) Connection in Creative Virtual Teams" Proceedings of the IBAM, San Diego,.

Ohara-Devereaux, M. and R. Johansen. (1994) Global Work: Bridging Distance, Culture and Time. San Francisco: Jossey-Bass,.

Potter, R., R. Cooke \& P. Balthazard. (2000) Virtual Team Interaction: Assessment, Consequences, and Management. Team Performance Management: An International Journal. \#6:131-137

Ragothaman, S. and D. Hoadley. (1997) Integrating the Internet and the World Wide Web Into the Business Classroom: A Synthesis." Education for Business. . March/April

Ratcliff, J.L. (editor) (1992) Assessment and Curriculum Reform. San Francisco: Jossey-Bass,.

Rockett L., J. Valor, P. Miller \& P. Naude. (1998) Technology and Virtual Teams: Using Globally Distributed Groups in MBA Learning Campus-Wide Information Systems,. \#15:174-182.

Saltzberg, S. and S. Polyson. (1995) Distributed Learning on the World Wide Web. Syllabus, 9(1), 26-28.

Shepperd, J.A. (1993) Productivity Loss in Performance Groups: A Motivation Analysis. Psychological Bulletin,. \#113:67-81

Simons, D. (1999) Closing the Gap on Distance Learning. BusinessWest. August,.

Solomon, C.M. (1998) Sharing Information Across Borders and Time Zones Workforce, 12-17.

Tinto, V. (1999) Taking Retention Seriously: Rethinking the First Year of College. NACADA Journal, 19:5-9.

Tonn, J.C. \& Milledge, V. (2002) Team Building in an MBA "Gateway" Course: Lessons Learned. Journal of Management Education, 26, 415-428. 
Townsend, A. and S.M. DeMarie. (1996) "Are You Ready for Virtual Teams?" $\underline{\text { HR }}$ Magazine. 41:123-128.

Treadwell, T.W. and E. Leach. (1998) Collaborative Teaching Over the Internet. Journal of Management Education. August,. Volume 22: 498.

Watson, B.S. (1995) The New Training Edge Management Review. May,: 49-51.

Wiedmer, T.L. (1998) Digital Portfolios: Capturing and Demonstrating Skills and Levels of Performance. Phi Delta Kappan, Volume 79:586. 